\title{
K and L- shell X-ray Transition-Probability Ratios by Proton Bombardment
}

\author{
P.K. Prajapati ${ }^{1 *}$ and Ajay Kumar ${ }^{2}$ \\ ${ }^{1}$ Dept. of Physics, Institute of Science, Banaras Hindu University, Varanasi, India \\ ${ }^{2}$ Dept. of Physics, Institute of Science, Banaras Hindu University, Varanasi, India \\ *Corresponding Author: pkpbhu13@gmail.com
}

Available online at: www.isroset.org

Accepted: 14/Aug/ 2018, Online:31/Aug/2018

\begin{abstract}
The present work aimed to study the energy dependence of $\mathrm{K}_{\alpha} / \mathrm{K}_{\beta}$ X-ray transition-probability ratios for the elements $\mathrm{Fe}, \mathrm{Cu}, \mathrm{Se}, \mathrm{Ag}$ and $\mathrm{L}_{\alpha} / \mathrm{L}_{\beta}, \mathrm{L}_{\alpha} / \mathrm{L}_{\gamma}$ and $\mathrm{L}_{\alpha} / \mathrm{L}_{1} \mathrm{X}$-ray transition-probability ratios for the elements $\mathrm{Ag}, \mathrm{Pb}$ and $\mathrm{Bi}$. It has been measured by proton bombardment in the energy range of 1.5 to $3.0 \mathrm{MeV}$. Our results provide constant transitionprobability ratios for $\mathrm{K}$ shell X-ray with varying proton energies, while for L X-ray, transition probability ratios show variation with incident proton energy. X-ray transition probability has been compared with the theoretical ratios, calculated by relativistic Hartee-Slater theory and using sub-shell direct ionization cross-sections.
\end{abstract}

Keywords - PIXE, X-ray Transition Probability,Emmision rate, Fluorescence yield, ECPSSR theory,Inner-shell ionization cross section.

\section{INTRODUCTION}

Accurate atomic data such as X-ray transitions- probability ratios, fluorescence yields and Coster-Kronig transition probability, are important for applications of trace element analysis by Particle Induced X-ray Emission (PIXE), X-ray Fluorescence (XRF) and fundamental physical processes studies of ion-atom collisions. Several experimental as well as theoretical data for X-ray transition probability ratios has been reported [1-7], but our aim was to measure X-ray transition probability ratios through PIXE (Proton Induced $\mathrm{X}$-ray emission) from 1.5-3.0 MeV. PIXE measurement is a non destructive trace elemental analysis being done in this energy range. Low $\mathrm{Z}$ elements are determined by $\mathrm{K} X$-ray, where as high $\mathrm{Z}$ elements are determined by $\mathrm{L} \mathrm{X}$-ray, due to poor detection efficiency of $\mathrm{Si}(\mathrm{Li})$ detector at high energy $\mathrm{K}$ $\mathrm{X}$-ray. For this we have selected low $\mathrm{Z}$ elements ( $\mathrm{Fe}, \mathrm{Cu}, \mathrm{Se}$, $\mathrm{Ag}$ ) to measure $\mathrm{K}$ shell $\mathrm{X}$-ray transition probability ratios and high $\mathrm{Z}$ elements $(\mathrm{Ag}, \mathrm{Pb}, \mathrm{Bi}$ ) to measure $\mathrm{L}$ shell $\mathrm{X}$-ray transition probability ratios with consecutive atomic number 82 and 83. Transition probability directly related with X-ray production cross section and X-ray cross section is directly related with concentration of element [8]. Experimental X- ray transition probability ratios are required for testing the validity of the theories on inner-shell ionization by proton. Measured K-shell X-ray transition probability ratios has been compared with theoretical ratios calculated by J.H. Scofield with the help of relativistic Hartee-Slater theory [9-10], while L-shell X-ray transition probability ratios are calculated by using the method of G.A.Bissinger [11] in which we have calculated direction ionization cross section by ECPSSR theory [12-14]. This theory is enable to calculate direct ionization cross section by Proton. ECPSSR theory is the modified form of the Plane wave Born approximation (PWBA) theory and it includes the effect of projectile energy loss (E), Coulomb deflection of the projectile (C), polarization effects of the target electron and relativistic effects (R).The accuracy of the measurement mainly depends on the detection efficiency of the detector for both $\mathrm{K}$ and Lshell X-ray. PIXE measurement sensitivity is up to the $\mathrm{ppb}$ level. Therefore choice of pure metallic targets become very important.

This paper has been organized into five distinct sectionsIntroduction, theoretical X-ray intensity calculation for Lshell, experimental details and data analysis, results, discussion and conclusion. The introduction section covers 
briefly about X-ray transition probability with PIXE and the importance of the method has been discussed. In theoretical $\mathrm{X}$-ray intensity calculation section, we have mentioned formula for calculating X-ray intensity for L-shell. The experimental details and data analysis section provides technical details related to the measurements. Results section provides variation of $\mathrm{K}$ and $\mathrm{L}$ sub-shell $\mathrm{X}$-ray tansition probability with varying energies of Proton. In the discussion and conclusion section, the results obtained are discussed and major conclusions drawn from the results are provided.

\section{THEORETICAL INTENSITY FORMULA.}

Theoretical intensity of L-shell X-ray can be calculated using the method of Ref. [11].

$$
\begin{gathered}
\mathrm{I}_{\mathrm{L} \alpha}=\left\{\left[\mathrm{n}_{1}\left(\mathrm{f}_{13}+\mathrm{f}_{12} \mathrm{f}_{23}\right)+\mathrm{n}_{2} \mathrm{f}_{23}+\mathrm{n}_{3}\right] \omega_{3}\right\} \mathrm{F}_{3 \alpha} \\
\mathrm{I}_{\mathrm{L} \beta}=\mathrm{n}_{1} \omega_{1} \mathrm{~F}_{1 \beta}+\left(\mathrm{n}_{1} \mathrm{f}_{12}+\mathrm{n}_{2}\right) \omega_{2} \mathrm{~F}_{2 \beta}+\left[\mathrm{n}_{1}\left(\mathrm{f}_{13}+\mathrm{f}_{12} \mathrm{f}_{23}\right)+\mathrm{n}_{2}\right. \\
\left.\mathrm{f}_{23}+\mathrm{n}_{3}\right] \omega_{3} \mathrm{~F}_{3 \beta} \\
\mathrm{I}_{\mathrm{L} \gamma}=\mathrm{n}_{1} \omega_{1} \mathrm{~F}_{1 \gamma}+\left(\mathrm{n}_{1} \mathrm{f}_{12}+\mathrm{n}_{2}\right) \omega_{2} \mathrm{~F}_{2 \gamma} \\
\mathrm{I}_{\mathrm{LL}}=\left\{\left[\mathrm{n}_{1}\left(\mathrm{f}_{13}+\mathrm{f}_{12} \mathrm{f}_{23}\right)+\mathrm{n}_{2} \mathrm{f}_{23}+\mathrm{n}_{3}\right] \omega_{3}\right\} \mathrm{F}_{3 \mathrm{l}} \\
\text { Ionization cross-section ratio, } \\
\mathrm{n}_{1}=\sigma_{\mathrm{L} 1} / \sigma_{\mathrm{L} 3} \\
\mathrm{n}_{2}=\sigma_{\mathrm{L} 1} / \sigma_{\mathrm{L} 3} \\
\mathrm{n}_{3}=1
\end{gathered}
$$

Symbol, $F_{3 \alpha}, F_{1 \gamma}, F_{3 \iota}, F_{2 \gamma}, F_{2 \beta}$ represent fraction of radiative transition for L sub-shell [15].

$\mathrm{f}_{12}, \mathrm{f}_{13} \mathrm{f}_{23}$ and $\omega_{1}, \omega_{2}, \omega_{3}$ are Coster-Kronig yields, fluorescence yields respectively taken from Campbell work [16]. $\sigma_{\mathrm{L} 1}, \sigma_{\mathrm{L} 2}, \sigma_{\mathrm{L} 3}$ are sub-shell direct ionization cross sections, calculated using ECPSSR theory Ref.[9-11].

\section{EXPERIMENTAL DETAILS AND DATA ANALYSIS}

Thin metallic targets were prepared by thermal evaporation method on $10 \mu \mathrm{g} / \mathrm{cm}^{2}$ Mylar backing. The thicknesses of targets were of the order of few hundred $\mu \mathrm{g} / \mathrm{cm}^{2}$. The targets were mounted on ladder in vacuum chamber, which is designed for PIXE measurement at Ion Beam Laboratory (IBL), IOP Bhubaneshwar, India. Proton beam of variable energy ranges from $1.5 \mathrm{MeV}$ to $3.0 \mathrm{MeV}$ having beam size $2 \mathrm{~mm}$ and beam current 5-9 $\mathrm{nA}$, was bombarded by $3.0 \mathrm{MV}$ Pelletron accelerator. The X-ray detector was a $\mathrm{Si}(\mathrm{Li})$ detector having a $1.28 \mu \mathrm{m}$ Be window and energy resolution of $165 \mathrm{eV}$ at $5.9 \mathrm{keV}$. The angle between X-ray detector and beam direction was $90^{\circ}$. Targets were positioned on ladder in such a way that the target makes $45^{\circ}$ w.r.t. proton beam direction. In reaching to the detector; X-ray traversed a $20 \mu \mathrm{m}$ Mylar window and $5.0 \mathrm{~cm}$ in air. The energy calibrations of spectrum has been done by using standard X-ray sources ${ }^{56} \mathrm{Fe}$ and ${ }^{241} \mathrm{Am}$. X-ray detection efficiency as a function of energy has been taken from Ortech company[18], for detector $\mathrm{Si}(\mathrm{Li})$ Model No. SLP-06 165 OPT- 0.5. K X-ray were analyzed by Origin fitting software and L subgroup X-ray by Candle software which is freely available on official site of IUAC, New Delhi. Targets thicknesses were arranged in such a way that there was no significant absorption of K X-Ray and but absorption correction has been done for $\mathrm{L}$ X-ray lines. Theoretical intensity ratio of L-shell X-ray has been calculated using the method used in Ref. [11].

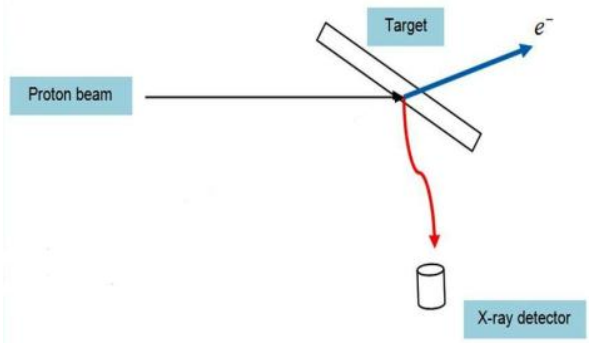

Figure 1: Schematic diagram of the experimental set-up.

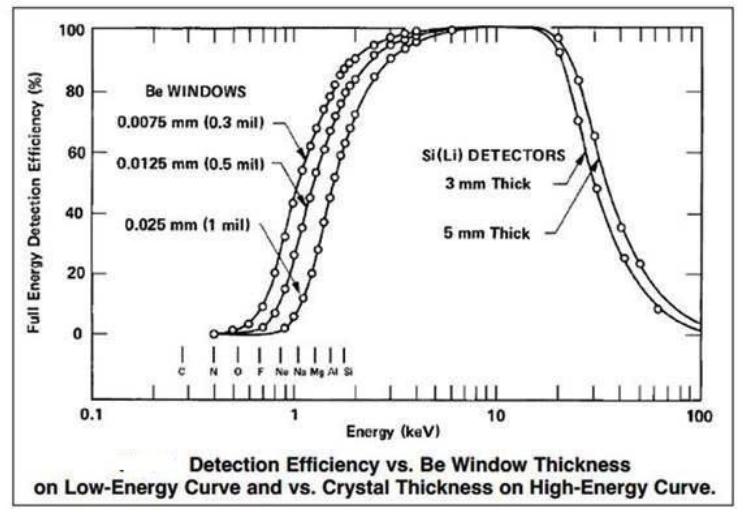

Figure 2: X-ray detection efficiency variation with photon energy Ortech Company, for detector Si(Li) Model No.SLP-06 165 OPT- 0.5. 


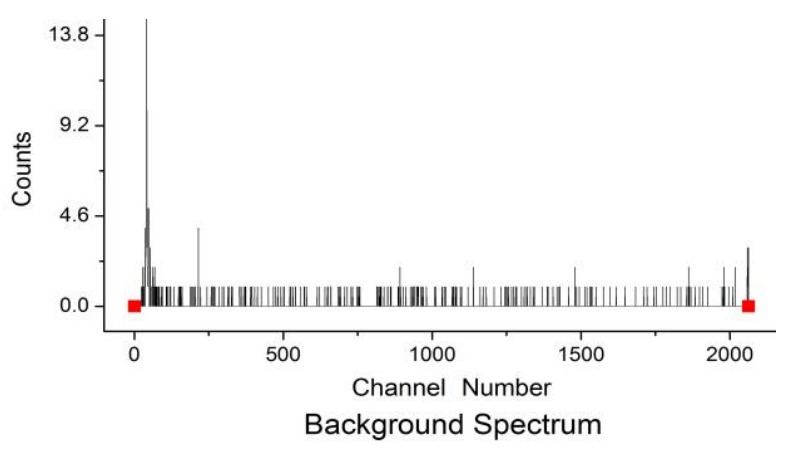

Figure 3: Background spectrum of target holder.

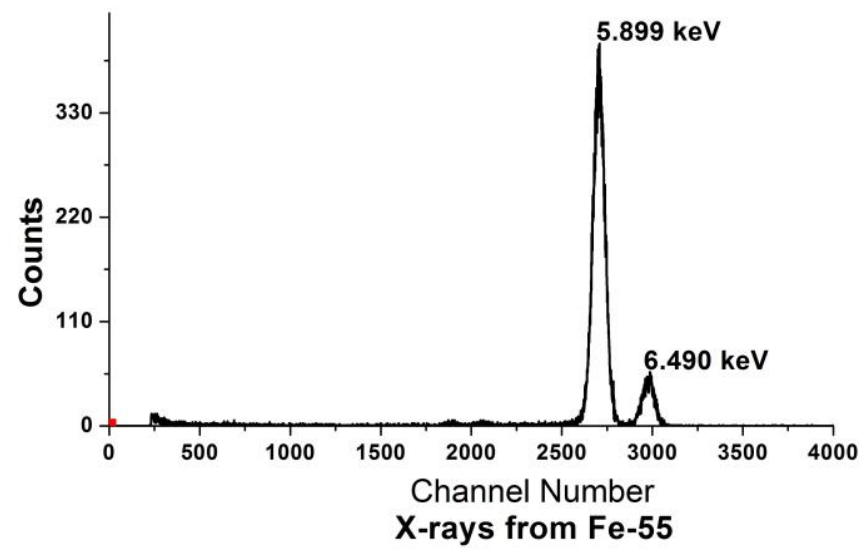

Figure 4. Spectrum of ${ }^{55} \mathrm{Fe}$ X-ray source for energy calibration.

\section{RESULTS}

Characteristics X-ray spectra of $\mathrm{Cu}$ and $\mathrm{Pb}$ element are shown in figures (7) and (11), transition probability ratios of $\mathrm{K}_{\alpha} / \mathrm{K}_{\beta} \mathrm{L}_{\alpha} / \mathrm{L}_{\beta}$ and $\mathrm{L}_{\alpha} / \mathrm{L}_{\gamma}$ are shown in tables.

Table 1. Experimental $\mathrm{K}_{\alpha} / \mathrm{K}_{\beta}$ X-ray transition-probability ratios for the elements $\mathrm{Fe} . \mathrm{Cu}, \mathrm{Se}$ and $\mathrm{Ag}$.

\begin{tabular}{|l|l|c|}
\hline Element & $\begin{array}{r}\text { Present } \\
\text { Work } \\
\mathbf{K}_{\boldsymbol{\alpha}} / \mathbf{K}_{\boldsymbol{\beta}}\end{array}$ & $\begin{array}{c}\text { Scofield } \\
\mathbf{K}_{\mathbf{\alpha}} / \mathbf{K}_{\boldsymbol{\beta}}\end{array}$ \\
\hline $\mathrm{Fe}$ & 7.2419 & 7.1890 \\
\hline $\mathrm{Cu}$ & 7.2727 & 7.2510 \\
\hline $\mathrm{Se}$ & 6.3573 & 6.1576 \\
\hline $\mathrm{Ag}$ & 4.7891 & 4.6948 \\
\hline
\end{tabular}

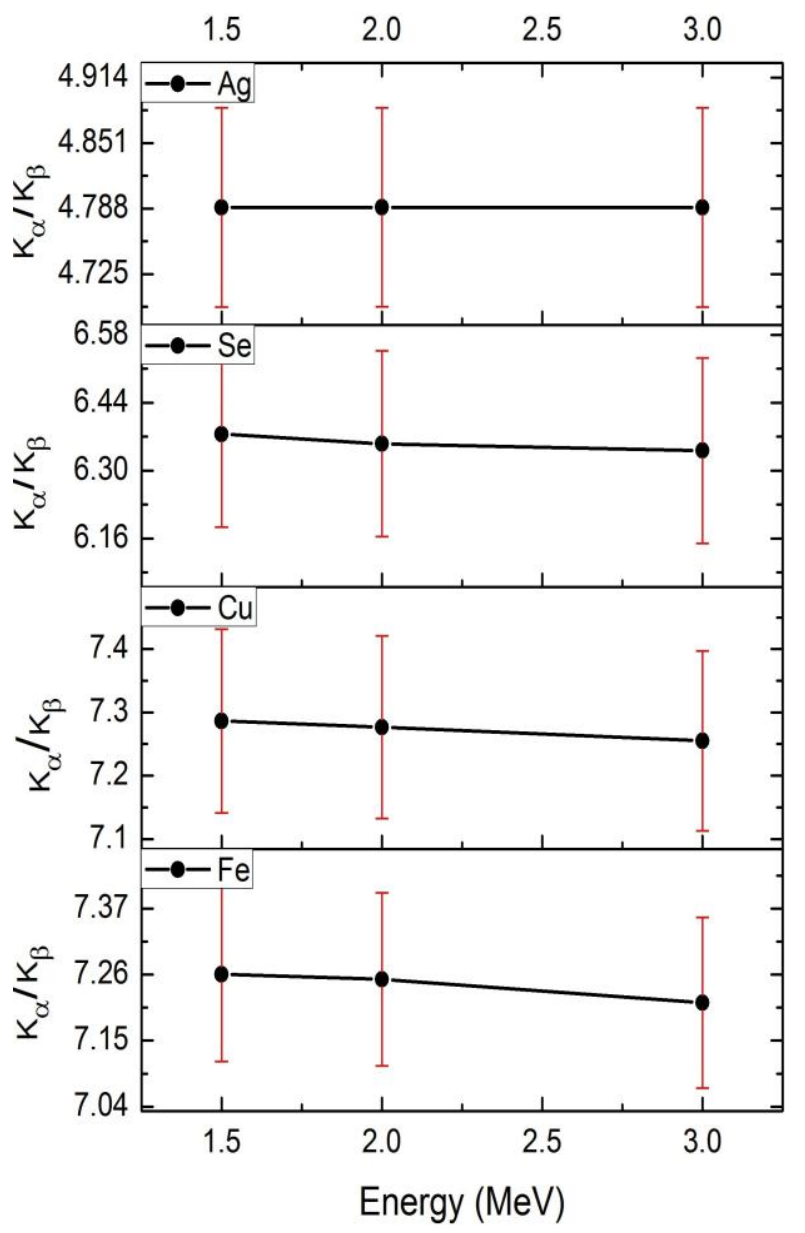

Figure 5: Variation of $\mathrm{K}_{\alpha} / \mathrm{K}_{\beta}$ ratios of $\mathrm{Fe}, \mathrm{Cu}$, Se and $\mathrm{Ag}$ with proton energy.

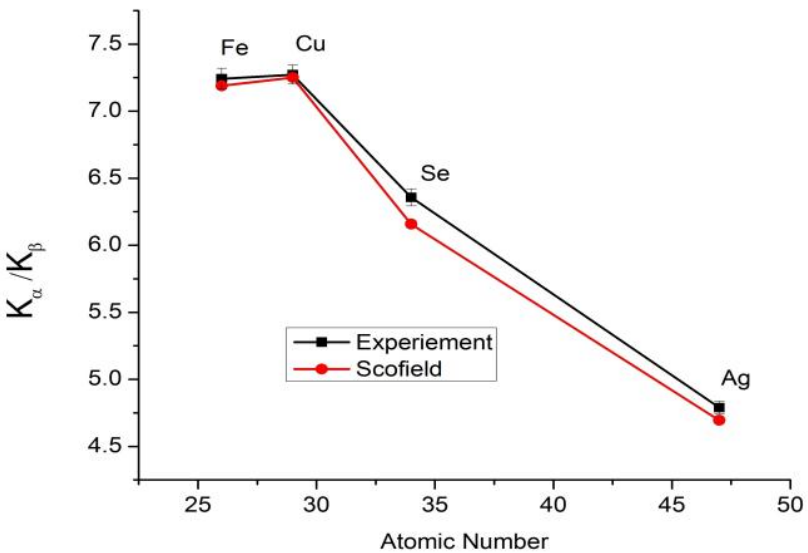

Figure 6: Variation of $\mathrm{K}_{\alpha} / \mathrm{K}_{\beta}$ ratio with Atomic number. 
It is clear from our measurement that ratios $\mathrm{K}_{\alpha} / \mathrm{K}_{\beta}$ are independent from projectile energy and ratios decrease with increase of atomic number.

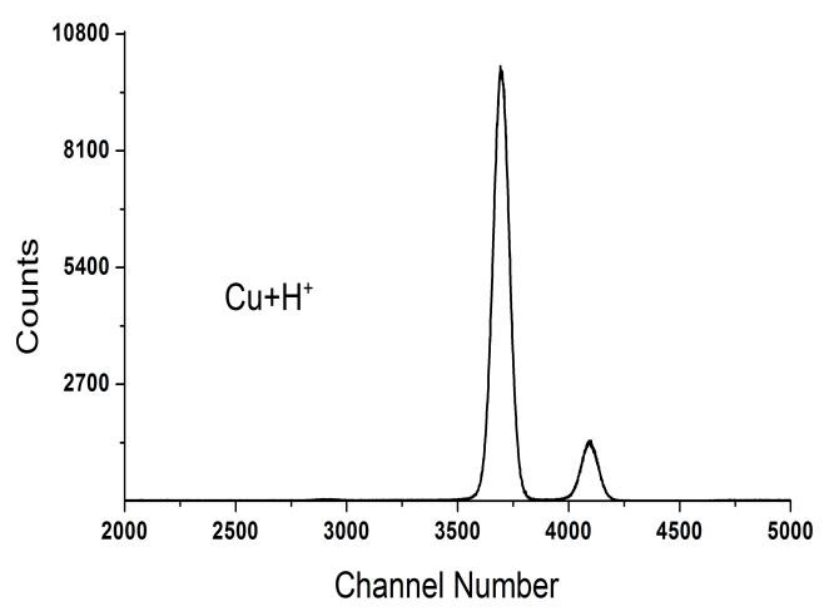

Figure 7: K-shell characteristics $\mathrm{X}$-ray spectrum of $\mathrm{Cu}$ produced by 1.5 $\mathrm{MeV}$ Proton.

Table 2. Energy dependence of experimental X-ray transition-probability ratios $\left(\mathrm{L}_{\alpha} / \mathrm{L}_{\beta}\right)$ for the elements $\mathrm{Ag}, \mathrm{Pb}$, and $\mathrm{Bi}$.

\begin{tabular}{|l|l|l|l|}
\hline Element & $\begin{array}{c}\mathbf{L}_{\alpha} / \mathbf{L}_{\boldsymbol{\beta}} \\
(\mathbf{1 . 5} \mathbf{M e V})\end{array}$ & $\begin{array}{c}\mathbf{L}_{\boldsymbol{\alpha}} / \mathbf{L}_{\boldsymbol{\beta}} \\
(\mathbf{2 . 0} \mathbf{M e V})\end{array}$ & $\begin{array}{c}\mathbf{L}_{\boldsymbol{\alpha}} / \mathbf{L}_{\boldsymbol{\beta}} \\
(\mathbf{3 . 0} \mathbf{M e V})\end{array}$ \\
\hline $\mathrm{Ag}$ & 1.6846 & 1.6201 & 1.5118 \\
\hline $\mathrm{Pb}$ & 2.0257 & 1.9140 & 1.8385 \\
\hline $\mathrm{Bi}$ & 1.9888 & 1.9081 & 1.8301 \\
\hline
\end{tabular}

Table3. Energy dependence of theoretical X-ray transitions-probability ratios $\left(\mathrm{L}_{\alpha} / \mathrm{L}_{\beta}\right)$ for the elements $\mathrm{Ag}, \mathrm{Pb}$, and $\mathrm{Bi}$.

\begin{tabular}{|l|l|l|l|}
\hline Element & $\begin{array}{c}\mathbf{L}_{\boldsymbol{\alpha}} / \mathbf{L}_{\boldsymbol{\beta}} \\
(\mathbf{1 . 5} \mathrm{MeV})\end{array}$ & $\begin{array}{c}\mathbf{L}_{\boldsymbol{\alpha}} / \mathbf{L}_{\boldsymbol{\beta}} \\
(\mathbf{2 . 0} \mathrm{MeV})\end{array}$ & $\begin{array}{c}\mathbf{L}_{\boldsymbol{\alpha}} / \mathbf{L}_{\boldsymbol{\beta}} \\
(\mathbf{3 . 0} \mathbf{M e V})\end{array}$ \\
\hline $\mathrm{Ag}$ & 1.8793 & 1.8537 & 1.8264 \\
\hline $\mathrm{Pb}$ & 1.8722 & 1.7868 & 1.6674 \\
\hline $\mathrm{Bi}$ & 1.8778 & 1.7942 & 1.6747 \\
\hline
\end{tabular}

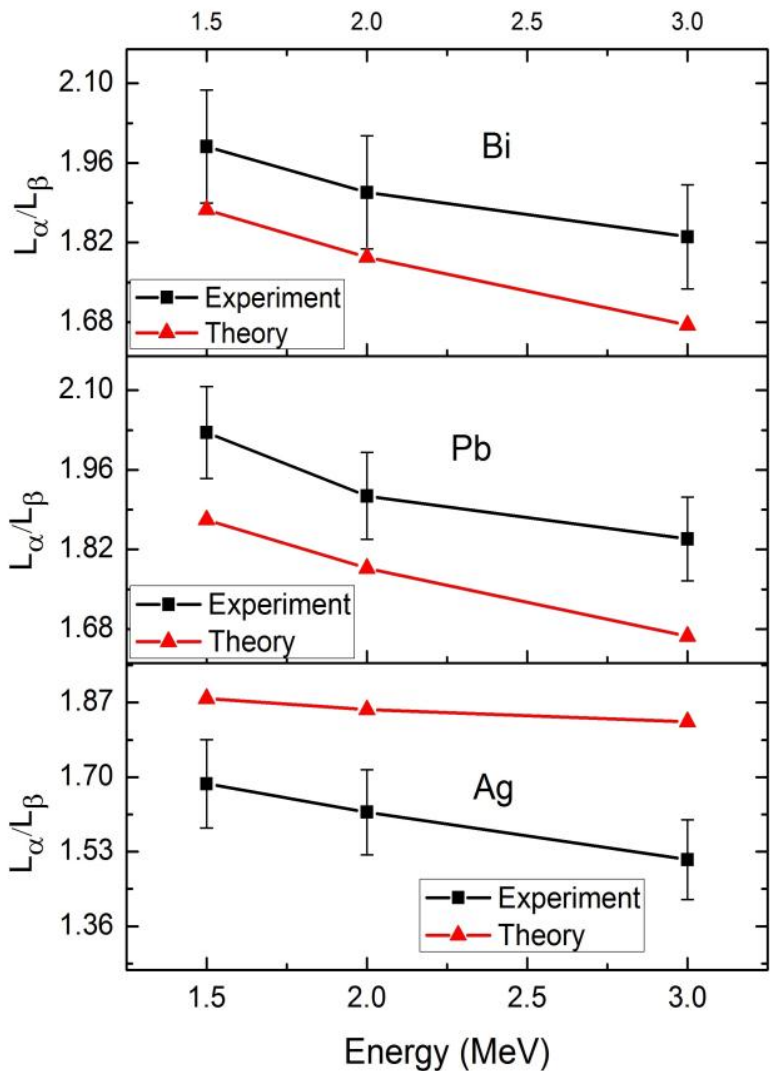

Figure 8: Variation of $\mathrm{L}_{\alpha} / \mathrm{L}_{\beta}$ ratio with energy for $\mathrm{Ag}, \mathrm{Pb}$ and $\mathrm{Bi}$ elements.

Table 4. Energy dependence of experimental X-ray transition-probability ratios $\left(\mathrm{L}_{\alpha} / \mathrm{L}_{\gamma}\right)$ for the elements $\mathrm{Ag}, \mathrm{Pb}$, and $\mathrm{Bi}$.

\begin{tabular}{|l|l|l|l|}
\hline Element & $\begin{array}{c}\mathbf{L}_{\mathbf{\alpha}} / \mathbf{L}_{\gamma} \\
(\mathbf{1 . 5} \mathbf{M e V})\end{array}$ & $\begin{array}{c}\mathbf{L}_{\mathbf{\alpha}} / \mathbf{L}_{\gamma} \\
(\mathbf{2 . 0} \mathbf{M e V})\end{array}$ & $\begin{array}{c}\mathbf{L}_{\boldsymbol{\alpha}} / \mathbf{L}_{\gamma} \\
(\mathbf{3 . 0} \mathbf{M e V})\end{array}$ \\
\hline $\mathrm{Ag}$ & 16.1496 & 15.9305 & 14.6516 \\
\hline $\mathrm{Pb}$ & 13.8441 & 12.6219 & 10.4588 \\
\hline $\mathrm{Bi}$ & 13.9007 & 12.6556 & 11.0300 \\
\hline
\end{tabular}

Table5. Energy dependence of theoretical X-ray transitions-probability ratios $\left(\mathrm{L}_{\alpha} / \mathrm{L}_{\gamma}\right)$ for the elements $\mathrm{Ag}, \mathrm{Pb}$, and $\mathrm{Bi}$. 


\begin{tabular}{|l|l|l|l|}
\hline Element & $\begin{array}{c}\mathbf{L}_{\boldsymbol{\alpha}} / \mathbf{L}_{\gamma} \\
(\mathbf{1 . 5} \mathbf{M e V})\end{array}$ & $\begin{array}{c}\mathbf{L}_{\boldsymbol{\alpha}} / \mathbf{L}_{\gamma} \\
(\mathbf{2 . 0} \mathbf{M e V})\end{array}$ & $\begin{array}{c}\mathbf{L}_{\boldsymbol{\alpha}} / \mathbf{L}_{\gamma} \\
(\mathbf{3 . 0} \mathbf{M e V})\end{array}$ \\
\hline $\mathrm{Ag}$ & 19.6637 & 19.1314 & 18.6722 \\
\hline $\mathrm{Pb}$ & 14.2635 & 13.0244 & 11.1637 \\
\hline $\mathrm{Bi}$ & 14.2994 & 13.0997 & 11.2299 \\
\hline
\end{tabular}

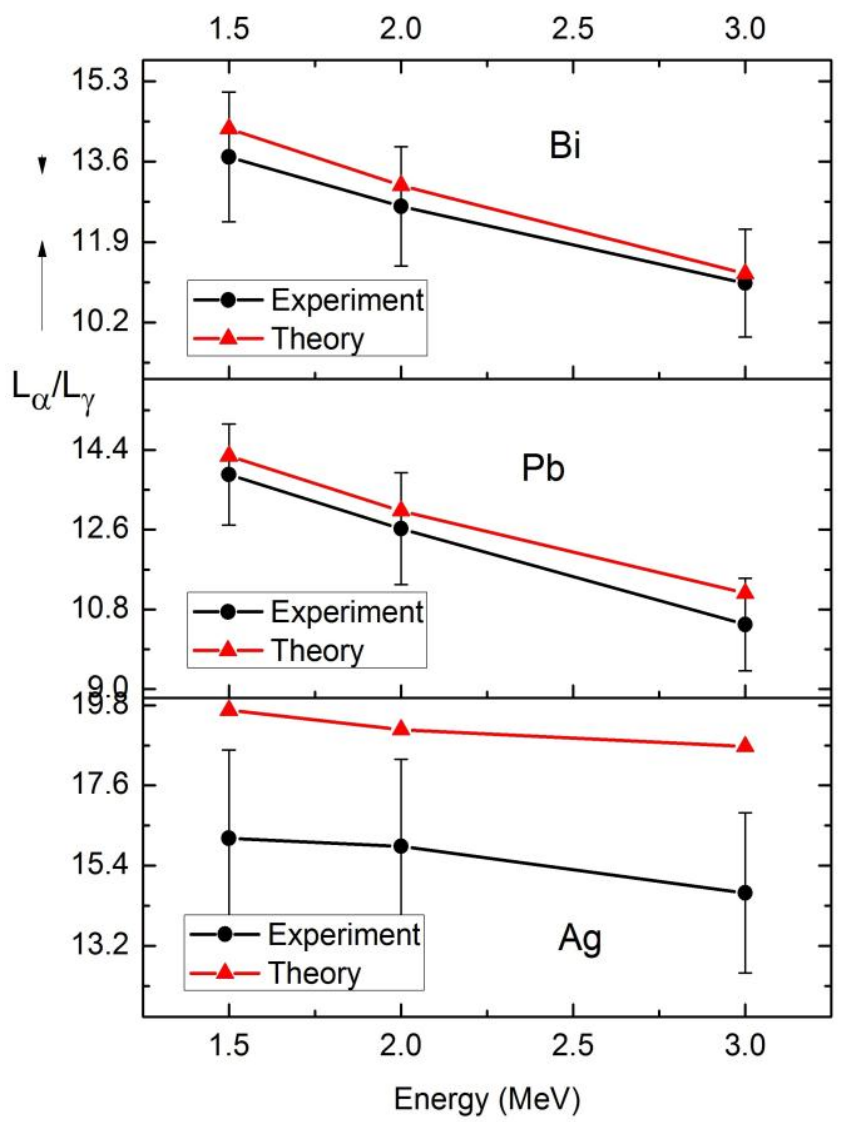

Figure 9: Variation of $\mathrm{L}_{\alpha} / \mathrm{L}_{\gamma}$ ratio with energy for $\mathrm{Ag}, \mathrm{Pb}$ and Bi elements. It is clear from our experimental and theoretical study that ratios $\mathrm{L}_{\alpha} / \mathrm{L}_{\beta}$ are dependent on projectile energy and ratios decreases with increase of projectile energy. Transition probability ratios $\left(\mathrm{L}_{\alpha} / \mathrm{L}_{\beta}\right)$ increases with the atomic number. Transition probability ratios $\left(\mathrm{L}_{\alpha} / \mathrm{L}_{\gamma}\right)$ also decreases with increase of projectile energy and atomic number.

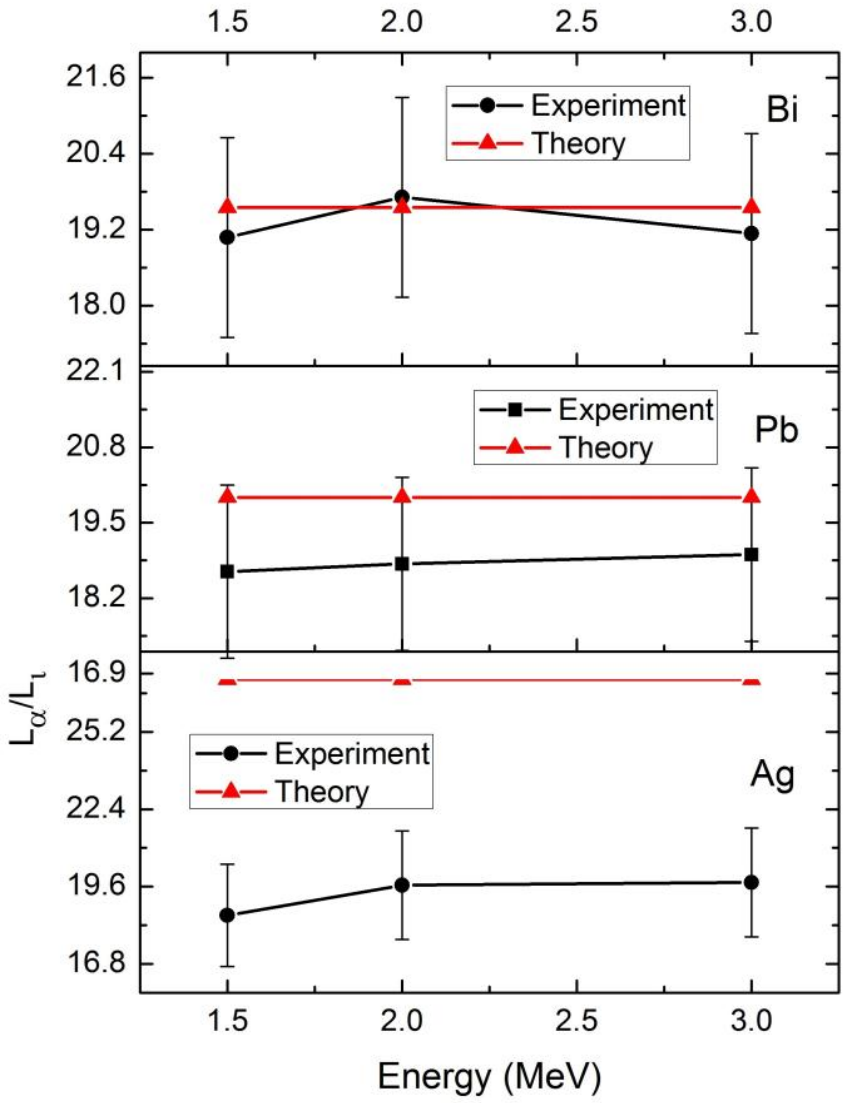

Figure 10: Variation of $\mathrm{L}_{\alpha} / \mathrm{L}_{1}$ ratios with energy for $\mathrm{Ag}, \mathrm{Pb}$ and $\mathrm{Bi}$ elements

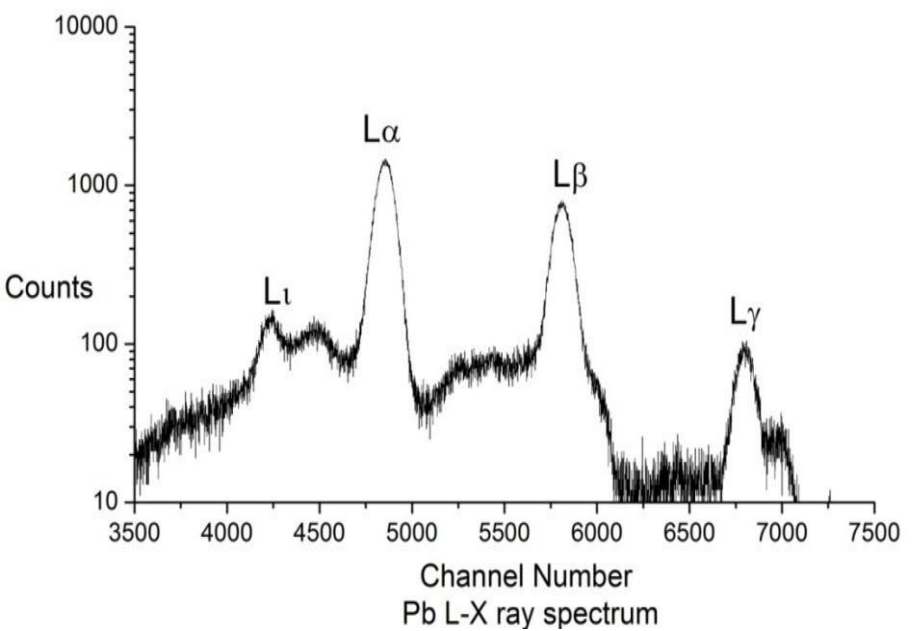

Figure 11: Typical characteristics L-shell $\mathrm{X}$-ray spectrum of $\mathrm{Pb}$ target induced by $1.5 \mathrm{MeV}$ Proton. 


\section{DiscuSSION AND CONCLUSION}

In the measurement of L-shell intensity ratio, some common factors such as geometrical efficiency and attenuation of $\mathrm{X}$ ray between target and X-ray detector are cancelled out. Thus $\mathrm{X}$-ray intensity ratio can be determined accurately with the background corrections. The experimentally measured $\mathrm{K}_{\alpha} / \mathrm{K}_{\beta}$ $\mathrm{X}$-ray transition-probability ratios are compared with the theoretical one calculated by J.H. Scofield [10]. The present data show good agreement with theory in comparison to other measured data $[1,6]$. It was found from the literature [6] that the $\mathrm{K}_{\alpha} / \mathrm{K}_{\beta} \quad \mathrm{X}$-ray transitions-probability ratios are independent from nature of excitation mechanism. Figure 5 also shows that $\mathrm{K}_{\alpha} / \mathrm{K}_{\beta} \mathrm{X}$-ray transition-probability ratios are independent from incident proton energy. From present measurement it is also verified that the intensity ratio increases as $\mathrm{Z}$ increases. The uncertainty in the $\mathrm{K}_{\alpha} / \mathrm{K}_{\beta} \mathrm{X}$-ray transitions- probability ratio is found to be on average about $2 \%$. The experimental values for the L-shell X-ray intensity ratios for $\mathrm{Ag}, \mathrm{Pb}$ and $\mathrm{Bi}$ at three excitation energies are listed in tables 2-5. The uncertainty due to statistical error for $\mathrm{L}_{\alpha} / \mathrm{L}_{\beta}$ ratio of the elements $\mathrm{Pb}, \mathrm{Bi}$ and $\mathrm{Ag}$ are 4-6\%.The uncertainty for $L_{\alpha} / L_{\gamma}$ ratios are $10-15 \%$ and in $L_{\alpha} / L_{1}$ ratios are $8-10 \%$ depending upon the counting statistics, incident particle energy and target thickness..For all the three elements L-X ray ratios $\mathrm{L}_{\alpha} / \mathrm{L}_{\beta}, \mathrm{L}_{\alpha} / \mathrm{L}_{\gamma}$ and $\mathrm{L}_{\alpha} / \mathrm{L}_{1}$ were measured and compared to ECPSSR theoretical intensity. Theoretical $\mathrm{L}_{\alpha} / \mathrm{L}_{\beta}$ ratio for Ag predicts about $17 \%$ higher w.r.t. experimental measured ratio at $3.0 \mathrm{MeV}$, while at $1.5 \mathrm{MeV}$ it is about $10 \%$. Our result for $\mathrm{Pb} \mathrm{L} \mathrm{L}_{\alpha} / \mathrm{L}_{\beta}$ is about $8 \%$ higher than those measured results [17] . For $\mathrm{L}_{\alpha} / \mathrm{L}_{\gamma}$ our results are $10 \%$ and $12 \%$ higher at 1.00 and $3.00 \mathrm{MeV}$, respectively. For the cases of $\mathrm{L}_{\alpha} / \mathrm{L}_{\beta}$ and $\mathrm{L}_{\alpha} / \mathrm{L}_{\gamma}$, the ECPSSR predictions lower with the measured data over the proton energy range $1.5-3.0 \mathrm{MeV}$ but it is higher when it compared with [7,17] for $\mathrm{Pb}$ and $\mathrm{Bi}$ at 3.0 $\mathrm{MeV}$. Our study indicates that the ratios $\mathrm{L}_{\alpha} / \mathrm{L}_{\mathrm{l}}$ are independent from incident proton energy theoretically as well as experimentally for all three targets. In case of $\mathrm{Bi}$, for $\mathrm{L}_{\alpha} / \mathrm{L}_{\beta}$ ratio theory predicts well within the experimental error at energy 1.5 and $2.0 \mathrm{MeV}$, while at $3.0 \mathrm{MeV}$ energy experimental ratio is higher about $10 \%$ with respect to theoretical value calculated by G.E.Bessignger et al.[11] and experimental values measured by D.A.Close et al. [7].

\section{ACKNOWLEDGMENT}

Author PKP expresses his gratitude to Prof. B.K.Singh, Department of Physics, BHU, Varanasi for encouragement and many helpful discussions relating to this work. Author wish to thanks Mr. S.S.Tiwary, who helped in recording the data. Author acknowledges use of the facilities of IOP, Bhubaneswar, India and the assistance of B. Mallick and S. Sahoo. Author also acknowledges to Dr. Horesh Kumar, who helped by providing materials for making of thin film.

\section{REFERENCES}

[1] J. N.Hansen,H.U.Freund and R.W.Fink "Relative transtion Probability of K shell" Nucl. Phys. A. Vol. 142,pp. 604-608,1970.

[2] G.E.Bessignger, S.M.Safroth and A.W.Waltner "Yields of $K$ and $L X$ Rays Arising from 2-30-Mev-Proton Bombardment of Ag" Physical Review A Vol. 5(2),pp. 2046-2052,1972.

[3] J.H.Scofield "Radiative Decay Rates of Vacancies in the $K$ and $L$ Shells” Physical Review Vol. 179 (1), pp. 09-16,1969.

[4] J. N.Hansen, H.U.Freund and R.W.Fink, "Relative $K-X$ ray transtion Probability of at $Z=90$ from ${ }^{249} \mathrm{Cf}$ decay" Nucl. Phys.A 153,pp. 465468,1970 .

[5] M.L.Garg,Jasbir Singh,H.R.Verma,Nirmal Singh,P. C. Mangal and P.N.Trehan "Relative intensity Measurement of L-shell x-ray for $\mathrm{Ta}, \mathrm{Au}, \mathrm{Pb}$ and $\mathrm{Bi}$ in the energy range 17-160 keV" J. Phys. B: At. Mol. Phys.Vol 17,pp. 577-584,1984.

[6] V.W.Silvinsky and P.J.Ebert " $K_{\alpha} / K_{\beta} X$-Ray Transition-Probability Ratios for Elements $18 \leq Z \leq 39$ " Physical Review A Vol. 5(4),pp. 1581-1586,1972.

[7] D.A.Close, R. C. Bearse, J. J. Malanify, and C. J. Umbarger "Yield Ratios $K_{\alpha} / K_{\beta}, L_{d} / L_{\beta}, L_{d} / L_{\gamma}$ and $L_{o} / L_{l}$ for $x$-ray produce by Proton of 1.0 to 3.7 Mev." Physical Review A Vol. 8,(4 )pp. 1873-1879, 1973.

[8] S.A.E. Jhonson and J.L.Campbell "A novel technique for elemental analysis"John Wiley \&Sons 1998.

[9] J.H. Scofield “ Relativistic Hartree-Slater values for $K$ and L X-ray emission rates", Atomic and Nuclear data tables,Vol.14, pp. 121-137 1974.

[10] J.H.Scofield "Exchange corrections of Ex-ray emission ratese'Physical Review A Vol. 9, (3),pp. 1041-1049,1974.

[11] G.E.Bessignger,A.B.Baskin,B.H.Choi,andS.M.Shafrothet "Relativistic Effects in Au L X-Ray Production by 0.5-3.0-MeV Protons" Physical Review A Vol. 6,(2),pp. 545-547,1972.

[12] W. Brandt and G. Lapicki "Energy-loss effect in inner-shell Coulomb ionization by heavy charged particles" Physical Review A Vol. 23 pp. 1717-1727, 1970.Phys, 1981.

[13] Grzegorz Lapicki and William Losonsky "Coulomb deflection in ion-atom collisions”,Physical Review A Vol.20 pp. 481-490,1979.

[14] Vladimir Horvat “ ERCSO8:A FORTRAN program equipped with a Window graphics user interface that calculate ECPSSR cross section 
for the removal of atomic electron", Computer Physics communication Vol. 180, pp. 995-1003, 2009.

[15] Krause M.O “Atomic Radiative and Radiationless Yields for $K$ and $L$ shells" J.Phys. Chem. Ref. Data, Vol.8 No.2,(1979) pp.307-327

[16] Campbell J.L." Fluorescence yields and Coster-Kronig probabilities for the atomic L subshells" Atomic Data and Nuclear Data Tables Vol.85, pp. 291-315,2003.

[17] C.E.Busch A. B. Baskin, P. H. Nettles, and S. M. Shafroth. “ "Study of the L- and M-Shell X Rays of Pb Produced by 0.5-14.0 MeV-Proton Beams" Physical Review A Vol. 7, (5),pp. 1601-1606,1973.

[18] Ortech Company,detection effciency of $\mathrm{Si}(\mathrm{Li})$ detector Model No.SLP06165 OPT- 0.5 .

\section{AUTHORS PROFILE}

Pradeep Kumar Prajapati is pursuing his $\mathrm{PhD}$ in Experimental Applied Nuclear and Atomic Physics, from Institute of Science, Department of Physics, Banaras Hindu University, Varanasi 221005, INDIA. He has 5 years of research experience.

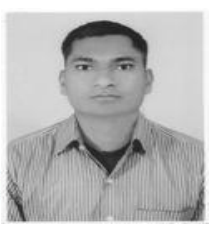

nas 5 years of research experience. 